This item was submitted to Loughborough's Research Repository by the author.

Items in Figshare are protected by copyright, with all rights reserved, unless otherwise indicated.

\title{
Exploring seat movement while driving - what do drivers think?
}

PLEASE CITE THE PUBLISHED VERSION

https://doi.org/10.1007/978-3-319-93885-1_52

PUBLISHER

(C) Springer

VERSION

AM (Accepted Manuscript)

\section{PUBLISHER STATEMENT}

This work is made available according to the conditions of the Creative Commons Attribution-NonCommercialNoDerivatives 4.0 International (CC BY-NC-ND 4.0) licence. Full details of this licence are available at: https://creativecommons.org/licenses/by-nc-nd/4.0/

\section{LICENCE}

CC BY-NC-ND 4.0

\section{REPOSITORY RECORD}

Varela, Maria, Diane E. Gyi, Neil J. Mansfield, Bob Bateman, Tomokazu Furuya, and Akinari Hirao. 2019. "Exploring Seat Movement While Driving - What Do Drivers Think?". figshare. https://hdl.handle.net/2134/33258. 
Varela M and Gyi DE et al (2018). Exploring seat movement while driving - what do drivers think? International Conference on Applied Human Factors, 21-25 July 2018, Florida, USA.

\title{
Exploring seat movement while driving - what do drivers think?
}

\author{
Maria Varela ${ }^{1}$, Diane Gyi ${ }^{1, *}$, Neil Mansfield ${ }^{2}$, Bob Bateman ${ }^{3}$, Tomokazu Furuya ${ }^{4}$, \\ Akinari Hirao ${ }^{4}$ \\ ${ }^{1}$ Loughborough Design School, Loughborough University, United Kingdom \\ ${ }^{2}$ School of Science and Technology, Nottingham Trent University, United Kingdom \\ ${ }^{3}$ Nissan Technical Centre Europe, United Kingdom \\ ${ }^{4}$ Nissan Motor Company Limited, Japan
}

\begin{abstract}
Designing movement into automotive seating is a means of countering the detrimental effects of fixed sitting postures. Twelve participants (six males and six females) were recruited to perform two simulated drives of 30 minutes under two seat movement conditions, single blind and in a balanced order. Interviews were conducted to understand in detail participants' views regarding the seat movement itself and the new seat concept. A discomfort questionnaire and a seat experience scale were completed at minute 0 (baseline) and after 30 minutes of each drive. Discomfort scores were collected for body parts - neck, shoulders, upper back, lower back, buttock area, knees and ankles - and overall body. A five-point Likert scale was used to rate responses to the six descriptors on a seat experience scale. The data from interviews indicated positive effects such as feeling refreshed and improved concentration. Although all participants were aware of the seat movement they got used to it quickly - it generally did not affect their driving. The discomfort and seat experience ratings showed a trend for lower discomfort with the fore-aft seat movement condition. Driver seat movement should be as least disruptive as possible to the driver, very small, slow, smooth and slightly perceptible.
\end{abstract}

Keywords: Dynamic Seating · Driving Comfort · Automotive Seating

\section{Introduction}

Driving is characterized by static sitting, referred to in the literature as postural fixity, which leads to driver physical fatigue due to the static loading [1]. Seat technologies are available to promote driver passive posture variation such as different types of massage systems [2], also called microadjustment systems [3], support systems [4] or active systems [5]. Another type of technology that allows introducing movement into the driver seat is through seat configuration variation, which is the method explored in this study. As an example, Veen et al. [6] investigated a seat movement system in

\footnotetext{
* Corresponding author

Tel.: + 44-1509-223043.

E-mail address: D.E.Gyi@lboro.ac.uk
} 
which the backrest moved $1.5^{\circ}$ backwards and the seat cushion $1^{\circ}$ up and down (and back to the starting position) and concluded it had a beneficial effect on the wellbeing of the drivers.

An experimental study by the author has shown that there was less reported discomfort with seat movement while driving compared to no seat movement [7]. Using the methods, driving rig and movement conditions standardized from previous studies $[7,8]$, this paper reports on research conducted to understand in more detail the drivers' experience of the seat movement concept.

\section{Methodology}

\section{$2.1 \quad$ Sampling}

A sample of 12 participants (six males and six females) was recruited in the UK through local advertising. Permission to conduct the study was granted by the Loughborough University Ethical Advisory Committee in June 2017.

\section{$2.2 \quad$ Rig and seat design}

The driving rig was mounted on a 6 degrees-of-freedom Multi-Axis Vibration Simulator (MAViS) and the set-up replicated an automatic car with steering wheel, accelerator, brake pedals and an Infiniti Q30 Nissan seat (Fig. 1). 'Follow driving' modules were used for the driving simulation.

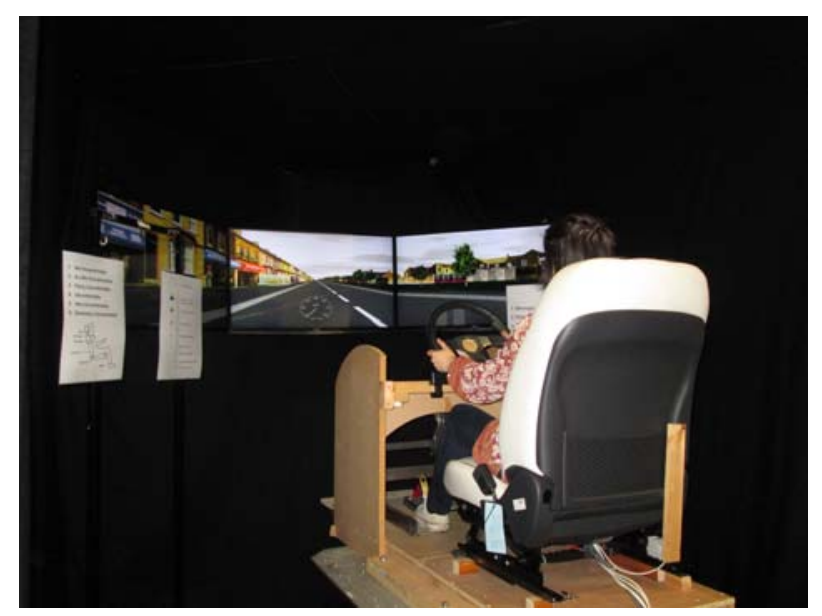

Fig. 1. Driving seat rig and Infiniti Q30 Nissan seat used in the study.

Remote electronic operation was used to deliver small, slow, smooth and slightly perceptible movement at a fixed speed. The two movement conditions were: 
- Fore-aft seat movement - Movement 1 (M1): 2 increments in each direction (1 increment $=8 \mathrm{~mm}$ ) over 15 minutes.

- Cushion and backrest angle movement - Movement 2 (M2): cushion - 5 increments in each direction $\left(1\right.$ increment $\left.=1.7^{\circ}\right)$ over 15 minutes, backrest -2 increments in each direction $\left(1\right.$ increment $\left.=0.5^{\circ}\right)$ over 15 minutes.

\subsection{Study design}

Before the first drive, each participant selected their optimum driving position using a fitting trial 'iterative' method. The same range of movement was delivered to each participant and therefore the seat adjustments were relative to the individuals' optimum driving position.

A 120-150 minute session involved two short simulated drives of 30 minutes. Movement was presented single blind and in a balanced order. A 10 minute recovery period was included between drives - Sammonds et al. [9] found this was the most effective break in terms of reduction of driver discomfort.

\subsection{Questionnaires}

Quantitative questionnaires were completed for each 30 minute drive at minute 0 (baseline) and after 30 minutes of driving:

- Discomfort questionnaire: discomfort scores were collected for body parts neck, shoulders, upper back, lower back, buttock area and ankles - this scale was adapted from ISO 2631-1. The overall scale was based on the Borg CR100 scale, adapted from Sammonds et al. [9]. An open question was also included asking if participants had discomfort in any 'other' body area.

- Seat experience scale: Descriptors for a 5 point Likert scale were used - 'I feel refreshed', 'I do not feel distracted', 'I feel comfortable', 'I do not feel irritated', 'I feel energized' and 'I feel relaxed' (based on Ahmadpour et al. [10]).

A qualitative questionnaire concerning their reactions to the movement was given at minute 15. After the 30 minute drive, participants were interviewed about their experiences of the movement while driving, for example, if they noticed it, if it influenced their comfort and preferred direction and range of movement. At the end of both drives, a de-brief interview was conducted where the context of research was introduced and they were asked their views on its potential, for example, influence on driving activity and acceptability for real world driving.

\section{$3 \quad$ Results and discussion}

\subsection{Sample}

Descriptives of the 12 drivers are presented in Table 1. 
Table 1. Descriptive data of the participants $(n=12)$.

\begin{tabular}{ll}
\hline \multicolumn{1}{c}{ Characteristics } \\
\hline Number & 12 \\
Gender & 6 male \& 6 female \\
Age & 19-50 years old (mean $28.9 \pm$ s.d.11.7) \\
Stature & $1495-1945$ mm (mean $1722.8 \pm$ s.d. 140.3) \\
Weight & $51.8-125.9 \mathrm{~kg}$ (mean $79.4 \pm$ s.d. 23.6) \\
\hline
\end{tabular}

\subsection{Interviews}

The audios from the interviews were analyzed by the researcher using NVivo software. After familiarization with the data, initial codes were generated, main themes were identified and then further sub-coded.

The short interviews (at minute 15 and minute 30) showed that all participants noticed the seat movement in the first minutes of the drive and that the majority got used to it quickly and found it generally not distracting or annoying. Regarding seat movement preferences, different views were expressed. For example, half would like more control over the directions and/or range of seat movement, some liked the seat movement as experienced in the trials and two reported that they would prefer a seat without movement.

Concerning the de-brief interviews (at the end of the two drives), the majority of participants reported that generally the seat movement did not affect their driving and feelings of safety. Positive effects on driving were in terms of 'making more room available' or improving comfort. A negative impact was identified 'when the backrest was moved back', as participants felt the need to lean forward to reach the steering wheel. With reference to concentration, the majority of drivers did not report negative influences, in fact positive effects of awakening and awareness were reported. Regarding the trust and acceptability of the seat movement feature, participants perceived that if the range of seat movement was in accordance with their preferences they would like to use the feature. Participants justified this due to feeling the movement was not drastic but subtle and therefore not dangerous.

With reference to when they were likely to use the seat movement feature, the majority of the drivers perceived benefits with long drives and motorway driving when their body 'stiffens up' or they need some 'extra movement' and also in terms of improving concentration. It was also pointed out that as town driving itself requires more driver movement (due to traffic lights, cornering, etc.), this movement feature may not be so necessary. Participants also pointed out that they felt they would use it more when feeling tired, for example, to help them concentrate and relax driving home from work.

\subsection{Discomfort and seat experience ratings}

Discomfort scores for body parts and overall discomfort were collected at minute 0 and 30 of each drive. For body part discomfort ratings after 30 minutes of driving, 
there was a non-significant trend for higher discomfort ratings with M2 for the shoulders, upper back, lower back, buttock area, knees and ankles (Fig. 2).

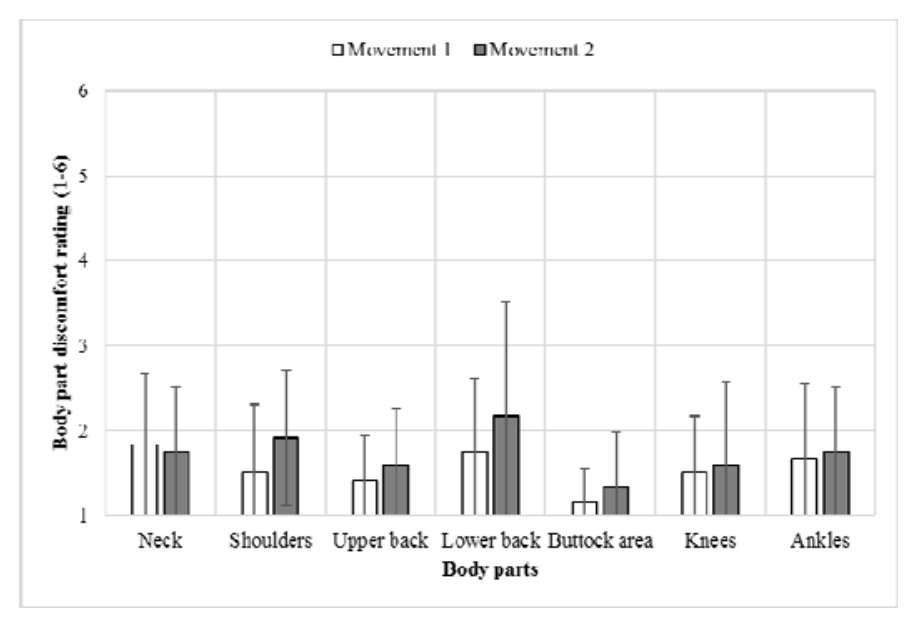

Fig. 2. Body part discomfort ratings for M1 (fore-aft) and M2 (cushion and backrest angle) after 30 minutes of driving $(\mathrm{n}=12)$.

Concerning the overall discomfort ratings at minute 30, a Wilcoxon signed-ranks test showed a statistically significant difference between conditions, with more overall discomfort for M2 ( $\mathrm{z}=-2.405, \mathrm{p}=0.016)$. Concerning overall discomfort at the start $(0$ minutes) and end (30 minutes) of the drive, there was also a statistically significant difference for M2 only, with more discomfort at the end of the drive $(z=-2.762$, $\mathrm{p}=0.003$ ).

In addition, with regard to the seat experience scale, after 30 minutes of driving a non-significant trend for lower ratings (a lower level of agreement) was found for M2, for the descriptors 'I feel refreshed', 'I do not feel distracted', 'I feel comfortable', 'I feel energized' and 'I feel relaxed'.

\subsection{The design concept}

The findings indicate that movement should be as least disruptive as possible (very small, slow, smooth and slightly perceptible). The movement in the experimental seat generally worked well, for example, frequency, sound and directions used, but the range used for backrest-back movement is likely to need decreasing. Many individual preferences were expressed from the interviews and there was no agreement on preferred direction (i.e., fore-aft, cushion and backrest angle movement). Despite this, in terms of reported discomfort over this short drive, there was a trend for lower discomfort with the fore-aft seat movement condition. 


\section{Conclusions}

The research advocates seat movement as a means of improving driver comfort. Overall seat movement should be very small, slow, smooth, slightly perceptible and with the least disruption to the driver. Although all participants were aware of the seat movement they got used to it quickly - it generally did not affect their driving. Positive effects such as feeling refreshed and improved concentration were reported. There was a trend for lower discomfort with the fore-aft seat movement condition, but this needs further exploration as subjective views varied. Long drives and motorway driving may be the most suitable for the use of the feature. Further data analysis will help understand links between participants' anthropometry (gender, age, stature and body weight) and their responses.

Acknowledgments. We would like to acknowledge the EPSRC CASE Award and Nissan Motor Company Limited for funding this research.

\section{References}

1. Gyi, D.E., 2013. Driving posture and healthy design. In: N. Gkikas, ed. Automotive ergonomics: driver-vehicle interaction. Boca Raton: CRC Press. pp.123-32.

2. Durkin, J.L., Harvey, A., Hughson, R.L. and Callaghan, J.P., 2006. The effects of lumbar massage on muscle fatigue, muscle oxygenation, low back discomfort, and driver performance during prolonged driving. Ergonomics, 49(1), pp.28-44.

3. Kolich, M. and Taboun, S.M., 2002. The effect of microadjustment on low back comfort in the context of automotive seating. International Journal of Vehicle Design, 29(4), pp.376-89.

4. Gruevski, K.M., Holmes, M.W.R., Gooyers, C.E., Dickerson, C.R. and Callaghan, J.P., 2016. Lumbar postures, seat interface pressures and discomfort responses to a novel thoracic support for police officers during prolonged simulated driving exposures. Applied Ergonomics, 52, pp.160-8.

5. Holmes, M.W.R., McKinnon, C.D., Dickerson, C.R. and Callaghan, J.P., 2013. The effects of police duty belt and seat design changes on lumbar spine posture, driver contact pressure and discomfort. Ergonomics, 56(1), pp.126-36.

6. Veen, S.V., Orlinskiy, V., Franz, M. and Vink, P., 2015. Investigating car passenger wellbeing related to a seat imposing continuous posture variation. Journal of Ergonomics, $5(3)$.

7. Varela, M., Gyi, D.E., Mansfield N.J., Picton R. and Hirao A., 2017. Designing movement into automotive seating - does it improve comfort? Proceedings of the First International Comfort Congress. 7-8 June 2017. Salerno. pp.3A -6.

8. Varela, M., Gyi, D. and Mansfield, N., 2016. Predicting the onset of driver musculoskeletal fatigue. In: P. Waterson, R. Sims and E-M Hubbard, eds. Proceedings of the International Conference on Ergonomics \& Human Factors. 19-21 April 2016. Daventry. pp.322-23.

9 Sammonds, G.M., Mansfield, N.J. and Fray, M., 2017. Improving long term driving comfort by taking breaks - How break activity affects effectiveness. Applied Ergonomics, 65, pp.81-9.

10. Ahmadpour, N., Robert, J.-M. and Lindgaard, G., 2016. Aircraft passenger comfort experience: Underlying factors and differentiation from discomfort. Applied Ergonomics, 52, pp.301-8. 